\title{
Technological and economic perspectives for development and manufacturing of cathode materials for lithium-ion batteries for transport industry
}

\author{
Yuri Koshtyal ${ }^{1,2}$, Maxim Maximov ${ }^{1,2 *}$, Denis Nazarov $^{1,2}$, Alexander Rumyantsev $^{1}$, and Qing \\ Sheng Wang ${ }^{3}$ \\ ${ }^{1}$ R\&D laboratory "Functional Materials", Peter the Great St. Petersburg Polytechnic University, \\ 195251 Polytechnicheskaya st. 29, Russian Federation \\ ${ }^{2}$ Center for National Technological Initiative "New Manufacturing Technologies", Peter the Great St. \\ Petersburg Polytechnic University, 195251 Polytechnicheskaya st. 29, Russian Federation \\ ${ }^{3}$ ENV (Zheijang) New Energy Material Technology Research Institute, 313100 Mingzhu Road 1278, \\ China
}

\begin{abstract}
Energy accumulators are one of the key directions of research and applied development in the spheres of power generation, saving and efficiency. Lithium-ion batteries (LIB) are widely used in portable power sources for modern electronics. However, currently the most perspective sphere of their use is transport industry. In this article we discuss the perspectives of using LIB in road vehicles manufacturing, as well as the main trends development of new cathode materials for LIB. In the medium-term perspective, the issue that is the closest to commercial use is related to nano-technologies and new materials (including nano-materials in LIB components (cathode, anode, electrolyte fluid, separator) that can raise the characteristics of these accumulators to a new level of quality and efficiency.
\end{abstract}

For the first time, the Lithium-ion battery (LIB) was used as a widely used power source by Sony in 1991. Due to its characteristics, such as high energy density, slow rate of selfdischarge, sustaining its capacity during the discharging and recharging cycles, lack of the memory effect etc. Lithium-ion batteries are widely used as a power source for various types of electronic devices [1]. In particular, they are used as a power source in such devices as smartphones, notebooks, electric vehicles, digital photographic and video cameras etc.

Lately, we can see steady growth in the market volume for Lithium-ion batteries. The largest relative growth is seen for to segments of LIB use - road vehicles (hybrid and electric cars, buses and trolleybuses) and power accumulators for industrial use (uninterrupted power sources, electric power storage in power generation and distribution systems) [2].

\footnotetext{
*Corresponding author: maximspbstu@mail.ru
} 
According to the forecasts from analysts of Credit Suisse, it is expected that, by 2030, sales of electric and hybrid vehicles will reach USD 400 billion, and the revenue from sales of batteries will exceed USD 100 billion [2]. Many vehicle manufacturers, such as Tesla, Nissan, General Motors, Mitsubishi etc. have already entered the market with a few generations of electric and hybrid vehicles. Considering the requirements for decreasing pollution from exhaust gases, as well as changes in demand, analysts from Berenberg expect that the demand for LIB for vehicles industry can become dominant as early as by 2021 (Fig. 1).

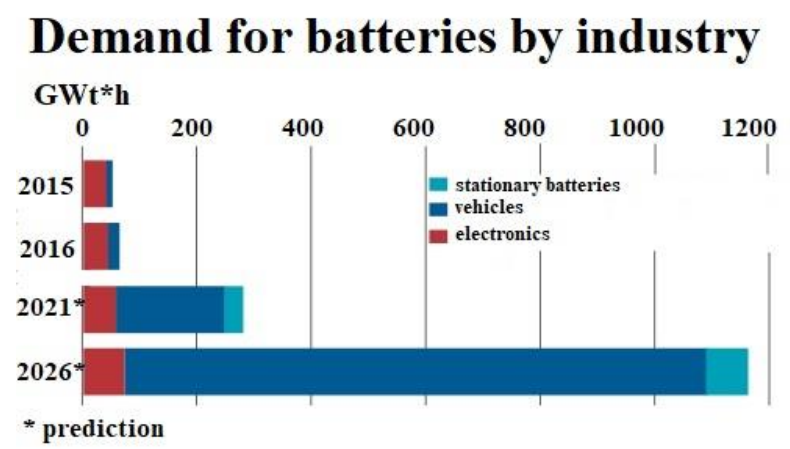

Fig. 1. Demand for LIB by industries, according to the data from Berenberg [3].

One example of a very successful commercialization of LIB is Tesla Motors that built a batteries manufacturing plant (Tesla Gigafactory) in 2016 in the Industrial Center in Tahoe Reno, in Storey County, Nevada, USA. According to the evaluation of the consulting company Benchmark, in the near future, more than 20 gigafactories will be manufacturing Lithium-ion batteries worldwide. Some of them are already operational; others will start manufacturing by 2021. Despite the success of Tesla Motors, manufacturing Lithium power sources is mainly based in Asia [4]. However, at the moment, Russia can already compete with China in respect of labor costs, which is a component in the cost of manufacturing, including manufacturing of Lithium-ion batteries. Therefore, if this trend remains, manufacturers may turn to stimulating development of LIB manufacturing in Russia.

The primary influence onto the price and characteristics of batteries is from the materials used - on average, about $74 \%$ (Fig. 2), with cathode materials being the main contribution to the cost [2].
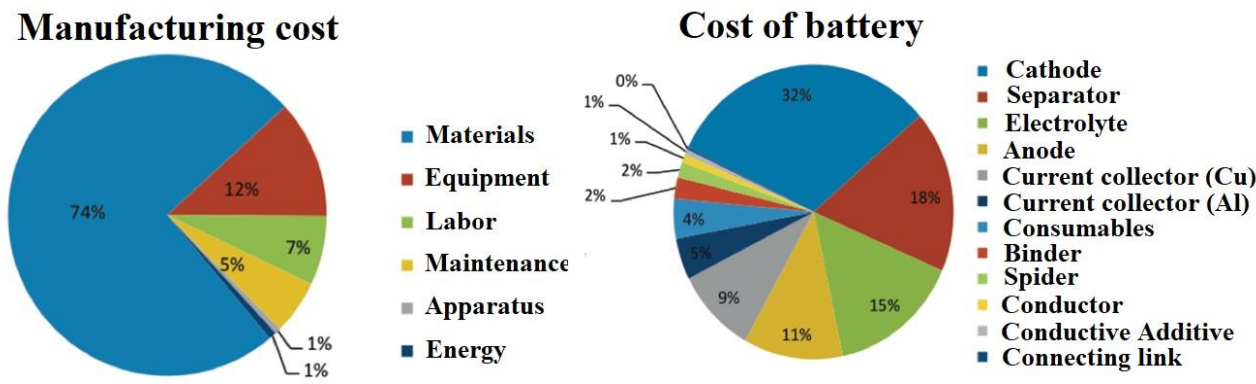

Fig. 2. Cost of LIB manufacturing and materials. 
The low level of competition in the Russian market of manufacturing cathode materials for Lithium-ion batteries, as well as a number of state programs for import substitution, opens wide perspectives for developing this industry. At the moment, manufacturing cathode materials in the territory of Russia is carried out by OJSC "CATHODE MATERIALS" based in Novosibirsk. At the same time, there are no large capacities for manufacturing cathode materials for LIB, and the growth in the volume of manufacturing can cause a significant decrease in the manufacturing cost. Besides, growing domestic competition will promote improvement of the product quality and the manufacturing technologies. OJSC "Novosibirsk Plant of Chemical Concentrates" (a part of the corporation "TVEL") is the only Russian manufacturer of pure Lithium products. OJSC "NZKH" supplies Lithium products to both the domestic market and abroad cooperating on the long-term basis with companies in the North America, Canada, Europe and the SouthEast Asia. Therefore, Russia has a large supplier of Lithium chemicals, which is an advantage, for transportation and customs costs are decreased.

In the territory of Russia, potential buyers of cathode materials are manufacturers and developers of Lithium-ion batteries: SMC Rigel (Saint-Petersburg); CJSC "NIIHIT-2", (Samara); CJSC IF “Orion-HIT", (Novocherkassk); OJSC "NIIAI "Istochnik", (SaintPetersburg); OJSC "Lithium-Element", (Saratov); OJSC "LioTech", (Novosibirsk) and others. Considering their high cost, Lithium-ion batteries made in Russia are mainly used in specialized machines. It is especially important for military production to manufacture all the components inside the country.

In highly developed industrial countries, the manufacturing technologies for Lithiumion batteries are being continuously improved with new developments regularly implemented into manufacturing, in particular, for cathode materials. It is expected that using nano-technologies will bring maximum effect both in characteristics improvement and cost decrease. In this respect, foreign manufacturers support many projects in the sphere of manufacturing new materials and, in particular, cathode materials and cathodes based on them and a new generation of Lithium-ion batteries using innovative technologies (program DOE - USA, EC programs).

Currently, the most used cathode material is lithiated Cobalt oxide. However, in the medium-term perspective, the share of lithiated oxides of Nickel-Cobalt-Manganese (with higher Nickel content) and new materials - Lithium- and Manganese-enriched nanocomposite lithiated oxides with laminated structure, materials with two or more atoms of Lithium in the structural formula (Fluorine-phosphates etc.)

It is noteworthy that, since first cathode material (Lithium cobaltate) was invented in the 1980-ies by John B. Goodenough [5] and used in manufacturing in early 1990-ies by Sony, less than ten years have passed. In 2008, industrial use started of the cathode material based on Lithium-Ferrum-phosphate (LFP) obtained in 1997. Therefore, development of new and improved cathode materials for Lithium power sources and their implementation for manufacturing has only been done very recently, about 10-15 years ago.

Currently, more sophisticated cathode materials are being introduced, such as $\mathrm{LiNi}_{0,33} \mathrm{Co}_{0,33} \mathrm{Mn}_{0,33} \mathrm{O}_{2}$ (NCM), $\mathrm{LiNi}_{0,8} \mathrm{Co}_{0,15} \mathrm{Al}_{0,05} \mathrm{O}_{2}$ (NCA) etc. (Table 1), where the content of transitory metals can vary depending of the conditions of use [2]. 
Table 1. Characteristics and use of the main cathode materials.

\begin{tabular}{|c|c|c|c|c|c|c|c|}
\hline \multicolumn{3}{|c|}{ Cathode materials } & \multicolumn{5}{|c|}{ Characteristics ( 10 is the maximum) } \\
\hline Name & $\begin{array}{l}\text { Metals } \\
\text { content }\end{array}$ & Main use & $\begin{array}{l}\text { Energy } \\
\text { capacity }\end{array}$ & Power & Safety & $\begin{array}{l}\text { Life } \\
\text { cycle }\end{array}$ & $\begin{array}{c}\text { Pric } \\
\text { e }\end{array}$ \\
\hline NCA & $\begin{array}{c}\mathrm{Li} / \mathbf{N i} / \mathbf{C o} / \\
\mathrm{Al}\end{array}$ & $\begin{array}{c}\text { Electric } \\
\text { vehicles/ } \\
\text { hybrid vehicles }\end{array}$ & 10 & 10 & 3 & 6 & 6 \\
\hline NCM & $\begin{array}{c}\mathrm{Li} / \mathbf{N i} / \mathbf{M n} / \\
\text { Co }\end{array}$ & $\begin{array}{c}\text { Electric } \\
\text { vehicles/ } \\
\text { hybrid vehicles }\end{array}$ & 6 & 6 & 6 & 10 & 10 \\
\hline LFP & $\mathbf{L i} / \mathbf{F e} / \mathbf{P}$ & $\begin{array}{l}\text { Uninterrupted } \\
\text { power sources }\end{array}$ & 2 & 10 & 10 & 6 & 6 \\
\hline LCO & $\mathbf{L i} / \mathbf{C o}$ & $\begin{array}{c}\text { Hybrid } \\
\text { vehicles/ } \\
\text { portable } \\
\text { electronics }\end{array}$ & 8 & 10 & 2 & 10 & 10 \\
\hline
\end{tabular}

Among the methods of synthesizing cathode materials are the following: depositing from solutions with subsequent thermal processing and crystallization, solutions (or aerosols) drying with air-spraying, hard-phase caking (including the mechanically activated chemicals) with certain temperature-time intervals, the sol-gel method and others. When comparing generis methods for synthesizing cathode materials, a conclusion can be drawn that using the sol-gel method is a more technologically complicated solution as it includes many auxiliary processes such as: flushing ions out of the cathode material and multi-stage drying. Besides, in order to cut the manufacturing cost, it is necessary to filtrate and recycle by-products of the cathode materials synthesis.

At the moment, due to high price of Cobalt, one of the most expensive cathode materials is Lithium cobaltate (LCO), but, as it has a number of undeniable advantages, (Table 1) it is the most widely used. The only drawback of $\mathrm{LiCoO}_{2}$ is its low safety that can be significantly improved through passivation (protective coating) with aluminum oxide [69]. As a perspective material for passivation, tin dioxide can also be considered that is also a feasible anode material for thin-film LIB [10-12]. Besides improving the safety, protective coating can increase the life cycle and capacity maintaining LIB $[13,14]$.

Among the methods for applying the coating on the surface of cathode materials, a method of atomic layer deposition (ALD) can be considered [15]. This technology is widely used for micro-processors manufacturing and passivation (encapsulation) of modern electronic displays; however, its use for manufacturing and modifying cathode materials has only been introduced recently. The main advantage of this method is the possibility to apply ultra-thin coatings (to several nano-meters) with high uniformity and integrity, directly on the material of the electrode that usually consists of micro- and nano-particles. For example, in the research of Dutch scientists [16] two main methods are described for manufacturing cathode materials with passivation coatings: applying coatings directly on the powder of the cathode material and on the cathode material in the structure of the LIB electrode. The authors said that, as the passivation coating is applied directly on the cathode material in the composition of the electrode, the electric contact between the particles is preserved (Fig. 3), which improves the electric-chemical characteristics. 


\section{Direct coating of the}

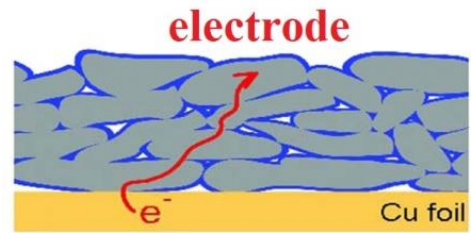

\section{Coating of particles}

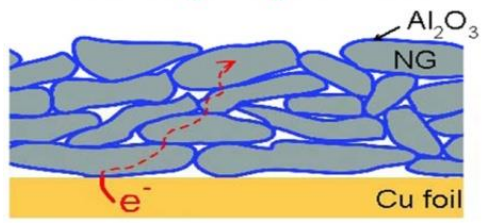

Fig. 3. A scheme of electrons transport with the coating applied on the electrode and the powder KM [16].

It is noteworthy that the technological method for applying functional coatings on electrodes can be introduced into the manufacturing cycle of LIB. This technological process has been already implemented in practice, and equipment manufacturers have presented industrial samples that can be adapted for particular uses. A schematic illustration of the principle of operation of actual manufacturing installations using the ALD method for flexible base plates that is called "Roll-to-Roll Spatial ALD" in the English-language literature is shown in Fig. 4. The process of application can be carried out under atmospheric or lower pressure, but does not require vacuum, which reduces the costs and simplifies manufacturing. This technology can be used not only for applying passivation coatings but also for other types of functional coatings, for example, the conductive coatings of various chemical compositions. Therefore the ALD technology has high adaptability and is also potentially usable for various electrode materials.
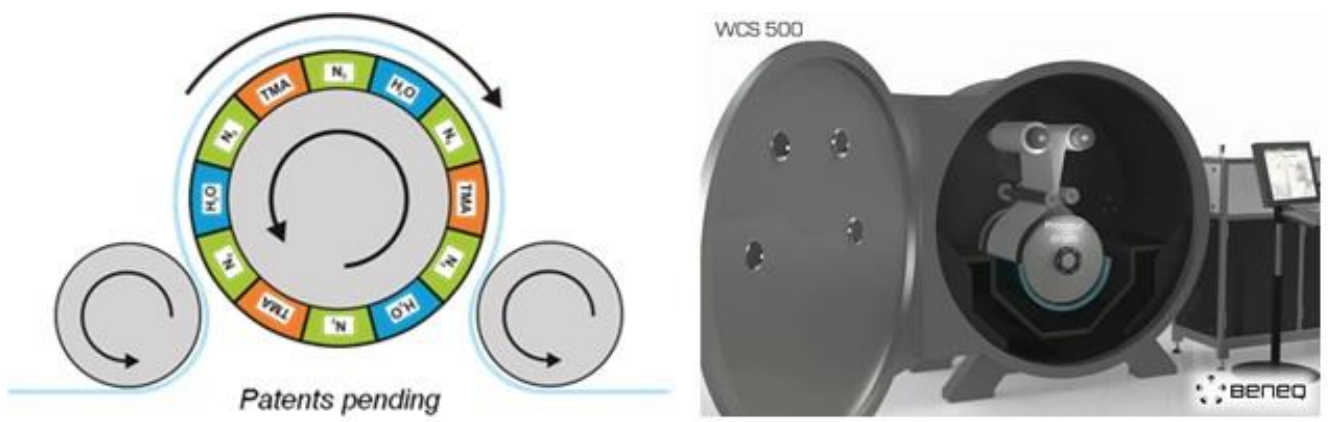

Fig. 4. A scheme of applying aluminum oxide coating on a film using the "Roll-to-Roll Spatial ALD" method and the equipment from Beneq Oy, Finland [17].

Using the atomic-layer depositing method for developing and manufacturing cathode materials can help achieve the leading position in the market of Lithium-ion batteries. The company "Pneumaticoat Technologies" (USA) already uses this technological approach for mass-production of cathode materials [18]. Fig. 5 shows a scheme and a photograph of the equipment. 


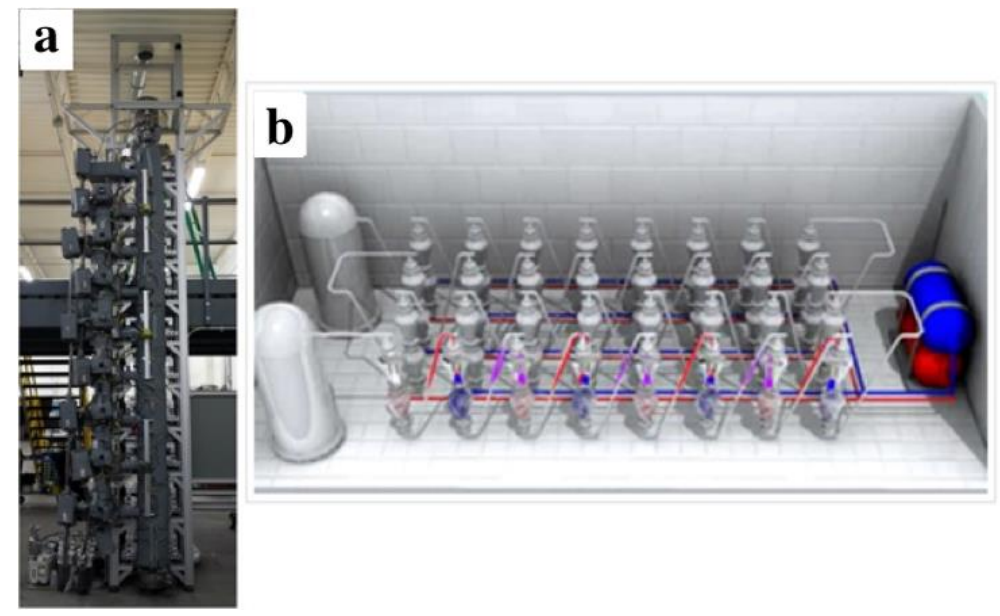

Fig. 5. Industrial implementation of the technology for applying thin film of various chemical compositions on powders using the ALD method. a) Equipment of the company "Pneumaticoat Technologies" based in Broomfield, Colorado (USA); б) A scheme of the applying process [18].

The red cylinder contains the metal-organic chemical that makes it possible to apply one nano-coating of $\mathrm{Al}_{2} \mathrm{O}_{3}, \mathrm{TiO}_{2}, \mathrm{ZrO}_{2}, \mathrm{BN}, \mathrm{AlN}, \mathrm{Pt}, \mathrm{W}, \mathrm{Co}, \mathrm{Fe}$ or others; the blue cylinder contains the additional chemical (water); Nitrogen is continuously fed from gray cylinders to maintain the suspended state of the powder in each of the small cameras, forming the "boiling layer". The consumption of all the three gases is monitored with electronic sensors so that the flow of the chemical or inert gas can be increased or decreased depending on the process stage of atomic-layer depositing.

In Russia, such projects were implemented in the R\&D group led by A.A.Popovich; in particular, a research was carried out to investigate the influence of the coating of aluminum oxide formed with the ALD method on flat electrodes (cathodes) for LIB manufacturing. As a result of the research for applying the coating and examining its electric-chemical properties according to newly developed programs and methods, it was estimated that, after 10 cycled of atomic-layer depositing of aluminum oxide with the layer thickness about $1 \mathrm{~nm}$, the cyclic life cycle of LIB grew by more than $30 \%$ [9]. The possibility was shown to apply ultra-thin aluminum oxide films with the ALD method on powder materials using a pseudo-suspended layer [19]. Therefore, a technology was developed to increase the life cycle of the battery by more than $30 \%$, which, at the present time, is a significant achievement under implementation.

As a conclusion, it is noteworthy that the leading LIB manufacturers widely use nanotechnologies and high-tech equipment to reinforce their leading position in manufacturing cathode materials and Lithium-ion batteries. In Russia, nano-technologies are primarily used for R\&D purposes. In particular, there are a number of R\&D laboratories and research centers in the leading universities and branches of the Academy of Sciences in Moscow, Saint-Petersburg, Novosibirsk, and Saransk developing the ALD technology; they have made scientific progress that enables achieving a significant breakthrough in using up-todate technologies for developing new materials for LIB manufacturing.

The research was carried out with financial support from the grant of the President of the Russian Federation for the state support of young Russian scientists - candidates of sciences; grant No. MK2961.2018.3. 


\section{References}

1. G. E. Blomgren, Journal of the Electrochemical Society, 164 (1) (2017)

2. G. Berckmans, M. Messagie, J. Smekens, N. Omar, L. Vanhaverbeke, J. Van Mierlo, Energies, 10 (2017)

3. According to materials published by vedomosti [online], Available at: https://www.vedomosti.ru/business/articles/2017/12/07/744439-proizvoditeliakkumulyatorov-gotovyatsya (2017)

4. K. Palmer, J. E. Tate, Z. Wadud, J. Nellthorp, Applied Energy 209 (2018)

5. K. Mitzushima, P. C. Jones, P. J. Wiseman, J. Goodenough, Materials Res. Bull., 15 (1980)

6. D. H. K. Jackson, M. R. Laskar, S. Y. Fang, S. Z. Xu, R. G. Ellis, X. Q. Li, M. Dreibelbis, S. E. Babcock, M. K. Mahanthappa, D. Morgan, R. J. Hamers, T. F. Kuech, J. Vac. Sci. Technol., A., 34 (3) (2016)

7. M. Xie, T. Hu, L. Yang, Y. Zhou, RSC Adv., 6 (68) (2016)

8. J. S. Park, X. B. Meng, J. W. Elam, S. Q. Hao, C. Wolverton, C. Kim, J. Cabana, Chem. Mater., 26 (10) (2014)

9. A. A. Popovich, M. Yu. Maximov, A. M. Rumyantsev, P. A. Novikov, J. Appl. Chem, 88 (5) (2015)

10. D. V. Nazarov, M. Yu. Maximov, P. A. Novikov, A. A. Popovich, A. O. Silin, V. M. Smirnov, N. P. Bobrysheva, O. M. Osmolovskaya, M. G. Osmolovsky, A. M. Rumyantsev, J. Vac. Sci. Technol., A., 35 (1) (2017)

11. M. Yu. Maximov, P. A. Novikov, D. V. Nazarov, A. M. Rymyantsev, A.O. Silin, Y. Zhang, A. A. Popovich, J. Electr. Mater., 46 (11) (2017)

12. A. A. Popovich, M. Y. Maximov, D. V. Nazarov, P. A. Novikov, A. O. Silin, A. I. Shamshurin, Rus. J. Appl. Chem., 89 (5) (2016)

13. J. Liu, X. Sun, Nanotechnology, 26 (2015)

14. A. A. Popovich, M. Yu. Maksimov, P. A. Novikov, A. O. Silin, D. V. Nazarov, A. M. Rumyantsev, Rus. J. Appl. Chem., 89 (4) (2016)

15. S. M. George, Chem. Rev., 110 (2010)

16. M. E. Donders, H. C. M. Knoops, W. M. M. Kessels, P. H. L. Notten, J. Electrochem. Society, 160 (5) (2013)

17. According to materials published by https://beneq.com/ [online], Available at: https://beneq.com/en/thin-films/products/roll-roll-ald/beneq-wcs-600 (2018)

18. Pneumaticoating [online], Available at: http://www.pneumaticoat.com/rdsystems.html (2018)

19. M. Yu. Maximov, A. S. Verevkin, A. A. Orlova, P. A. Novikov, A. O. Silin, O.V. Panchenko, A. A. Popovich, Journal of Ceramic Processing Research, 18 (2) (2017) 